\title{
Espectrometria de raios gama e emissão de radônio em solos da região do Maciço Sienítico Piquiri (Cachoeira do Sul e Encruzilhada do Sul, RS)
}

\author{
Gibran ROMERO-MUJALLI ${ }^{1}$ \& Ari ROISENBERG ${ }^{2}$
}

(1) Institute for Geology, University of Hamburg, Bundesstraße 55, 20146, Hamburg, Germany. E-mail: gibran.romero.mujalli@uni-hamburg.de.

(2) Departamento de Mineralogia e Petrologia, Instituto de Geociências, Universidade Federal do Rio Grande do Sul. Av. Bento Gonçalves, 9500, CEP 91.540-000, Porto Alegre, RS, Brasil. E-mail: ari.roisenberg@ufrgs.br.

Recebido em 02/2015. Aceito para publicação em 04/2016. Versão online publicada em 31/05/2016 (www.pesquisasemgeociencias.ufrgs.br)

\begin{abstract}
Resumo - Foram realizadas medidas de radiação gama e de concentração de radônio em solos da região do Maciço Sienítico Piquiri, região central do Estado do Rio Grande do Sul. Esta intrusão apresenta afinidade alcalina na qual a mineralogia acessória compreende presença relativamente abundante de titanita, apatita e zircão, entre outros minerais que podem conter elevadas concentrações de urânio. As medições de radiação gama foram feitas a partir de uma malha com quadrículas de 2 km de lado, utilizando o Espectrômetro de Radiação Gama RS-125, obtendo-se resultados em contagem por segundo (cps), taxa de dose (Dr) e concentrações de K, eU e eTh. As medidas de ${ }^{220} \mathrm{Rn}$ e ${ }^{222} \mathrm{Rn}$ no ar dos solos foram feitas com uso do equipamento AlphaGUARD. Os valores de cps obtidos neste estudo variam entre 130 e 1045, os de taxa de dose, entre 28,9 nSv/h e 424,6 nSv/h e as concentrações de K, entre $0,5 \%$ e 8,3 \%. As concentrações de eU se situam entre 0,8 ppm e 25,8 ppm, e as concentrações de eTh entre 3,0 ppm e 99,2 ppm. A distribuição de K permite definir com relativa precisão os contatos litológicos do Maciço sienítico Piquiri com as rochas adjacentes e entre as duas fácies (Fácies de Borda e Fácies Principal). As maiores concentrações de eTh estão na Fácies Principal do sienito, e as maiores concentrações de eU foram medidas na zona norte desta fácies. Os resultados de ${ }^{220} \mathrm{Rn}$ e ${ }^{222} \mathrm{Rn}$ para o ar contido no solo variam entre $10 \mathrm{kBq} / \mathrm{m}^{3}$ e $550 \mathrm{kBq} /$ $\mathrm{m}^{3}$ e entre $5 \mathrm{kBq} / \mathrm{m}^{3}$ e $400 \mathrm{kBq} / \mathrm{m}^{3}$, respectivamente, para a Fácies Principal e de Borda. As elevadas concentrações de Rn na Fácies Principal podem indicar potencial risco à saúde dos habitantes da área.
\end{abstract}

Palavras-chave: espectroradiometria, solo, sienito.

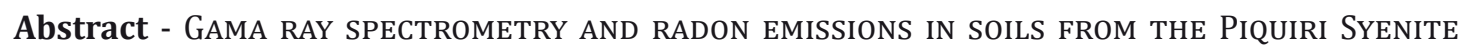
MASSif REgion (EncruzilHada do Sul E CACHoEIRA do Sul, RS). This study was focused in performing a gamma radiation survey and measurements of radon concentration in soils from the Piquiri Syenite Massif, an intrusion located at central area of the Rio Grande do Sul State. This intrusion has alkaline affiliation with high concentrations of uranium in accessory minerals as zircon, sphene, apatite, and others. The gamma radiation measurements were made considering a grid with squares about $2 \mathrm{~km}$ side each, using the gamma spectrometer RS-125, obtaining counts per second (cps), dose rate (DR) and concentrations of K, eU and eTh. Moreover, measurements of ${ }^{220} \mathrm{Rn}$ and ${ }^{222} \mathrm{Rn}$ in soil were made using the AlphaGUARD equipment. The counts per second values obtained in this study range from 130 to 1045 , the dose rate from $28.9 \mathrm{nSv} / \mathrm{h}$ to $424.6 \mathrm{nSv} / \mathrm{h}$, the $\mathrm{K}$ concentration from $0.5 \%$ to $8.3 \%$, the eU concentration from $0.8 \mathrm{ppm}$ to $25.8 \mathrm{ppm}$, and the eTh concentration from $3.0 \mathrm{ppm}$ to $99.2 \mathrm{ppm}$. The distribution of $\mathrm{K}$ defines with relatively precision the lithological contacts of the Piquiri Syenite Massif and between the two main facies of the intrusion (Main and Marginal Facies). The Main Facies of the syenite contains the highest concentrations of eTh, while the highest concentrations of eU were measured in the north area of this facies. The ${ }^{220} \mathrm{Rn}$ and ${ }^{222} \mathrm{Rn}$ concentrations range from $10 \mathrm{kBq} / \mathrm{m}^{3}$ to $550 \mathrm{kBq} / \mathrm{m}^{3}$ and from $5 \mathrm{kBq} / \mathrm{m}^{3}$ to 400 $\mathrm{kBq} / \mathrm{m}^{3}$, respectively, in the Main and Marginal Facies. The high values of radon measured in Main Facies of the Piquiri Syenite Intrusion may indicate high potential risk to the health of inhabitants in the area.

Key words: spectroradiometry, soil, syenite. 


\section{Introdução}

0 radônio $(\mathrm{Rn})$ é o gás nobre mais pesado, com um número atômico de 86 , encontrando-se na natureza retido nos minerais, dissolvido em águas subterrâneas e também como gás livre na atmosfera. Existem três isótopos naturais de radônio, o radônio-222 $\left({ }^{222} \mathrm{Rn}\right.$ ou radônio), radônio-220 $\left({ }^{220} \mathrm{Rn}\right.$ ou torônio $)$ e radônio- $219\left({ }^{219} \mathrm{Rn}\right.$ ou actinônio). Estes três isótopos de radônio provém do decaimento radioativo de isótopos de rádio, ${ }^{226} \mathrm{Ra},{ }^{224} \mathrm{Ra}$ e ${ }^{223} \mathrm{Ra}$, respectivamente (Ferronsky \& Polyakov, 2012). 0 actinônio $\left({ }^{219} \mathrm{Rn}\right)$ apresenta meia-vida muito baixa (3,92 segundos) e, devido à baixa ocorrência do ${ }^{235} \mathrm{U}$ (que inicia a serie radioativa natural), a abundância de ${ }^{219} \mathrm{Rn}$ na atmosfera é limitada (Appleton, 2005). No caso do torônio $\left({ }^{220} \mathrm{Rn}\right)$ a meia-vida é maior do que o actinônio (55,6 segundos), porém, é baixa em relação à do radônio $\left({ }^{222} \mathrm{Rn}\right)$, que apresenta um valor de 3,825 dias. Portanto, na maioria dos estudos ambientais, o isótopo de Rn mais estudado é o ${ }^{222} \mathrm{Rn}$, o qual, pode ser transportado por maiores distâncias do que os outros isótopos de Rn. Além disso, sua ocorrência está relacionada com a mobilidade do ${ }^{226} \mathrm{Ra}$, que, por sua vez, está relacionada com o comportamento geoquímico do ${ }^{238} \mathrm{U}$ (Appleton, op. cit.).

Os níveis relativamente elevados de $\mathrm{Rn}$ no ar estão relacionados diretamente com a geologia da área, dependendo do tipo de rocha. Em geral, rochas metamórficas e magmáticas com afinidade alcalina, folhelhos carbonosos, rochas carbonáticas e rochas fosfáticas possuem elevadas concentrações de urânio e rádio. Os folhelhos carbonosos podem acumular grandes quantidades de urânio devido ao ambiente de formação redutor, o qual reduz o íon uranila, encontrado nas águas $\left(\mathrm{UO}_{2}{ }^{2+}\right)$, precipitando-o na rocha. Por outro lado, o urânio nas rochas ígneas é encontrado em maior concentração naquelas de afinidade alcalina, como sienitos feldspatóidicos, granitos e granodioritos, bem como em seus correspondentes extrusivos (Appleton, 2005).

A taxa de liberação de Rn de rochas e solos é controlada pela concentração do urânio e pelo tipo de minerais nos quais o urânio ocorre. A solubilidade, o tamanho de grão dos cristais e a estrutura interna são os principais fatores que afetam a liberação do Rn. Geralmente, os solos liberam maiores quantidades de $\mathrm{Rn}$ do que as rochas, em razão do menor tamanho de grão e por sua porosidade natural (Appleton, 2005). A liberação do radônio a partir dos minerais e sua migração para a atmosfera, depende das características da rocha, da natureza do fluxo pelo qual é transportado, do clima, das características dos solos e das edificações (Appleton, op. cit.; Pascale et al., 2014).

A maior parte do Rn liberado para a atmosfera não representa um risco para a saúde humana. Contudo, o Rn pode ser acumulado dentro de edificações, cavernas e minas, em razão da baixa circulação de ar, afetando a saúde de quem circula nestes ambientes pela inalação do gás. A radiação gerada pelo Rn pode produzir mudanças em outros átomos ao seu redor, em decorrência da elevada capacidade de ionização. Assim, o Rn libera partículas alfa que, embora não penetrem profundamente nos materiais, provoca a ionização dos átomos, danificando tecidos orgânicos e, em certos casos, alterando o DNA dos organismos Por outro lado, o Rn também produz outros radionuclídeos instáveis que, por sua vez, podem ser precipitados nos pulmões dos seres vivos, em razão de sua afinidade na fase sólida, liberando partículas alfa ao decair (Appleton, 2005). Desta maneira, a exposição ao radônio por um tempo prolongado é relacionada ao surgimento de câncer de pulmão em humanos (WHO, 2009). Águas minerais radioativas representam águas com elevadas concentrações de ${ }^{226} \mathrm{Ra}$ e radônio, podendo acarretar nas pessoas câncer das vias digestivas, devido à sua ingestão (WHO, op. cit.).

No Brasil, o câncer de pulmão é uma das causas mais comuns de mortalidade em homens e em mulheres (Castro et al., 2004), despertando o interesse de pesquisadores sobre o risco associado à emissão de Rn. Nos últimos anos, alguns estudos têm sido desenvolvidos para determinar as concentrações de radônio em minas subterrâneas, águas subterrâneas, solos e ar (e.g., Buffon, 2002; Silva, 2005; Santos, 2008; Fianco et al., 2012). Neste particular, a Comissão Nacional de Energia Nuclear (CNEN) vem buscando parcerias e incentivando estudos no meio urbano.

Na região centro-leste do Estado Rio Grande do Sul, entre os municípios de Cachoeira do Sul e Encruzilhada do Sul, aflora o chamado Maciço Sienítico Piquiri, que representa uma intrusão de rochas de afinidade alcalina com altas concentrações de U e de elementos das terras raras leves (Nardi et al., 2007). As rochas que compõem este complexo têm tido uma demanda crescente como material ornamental, tanto no mercado nacional como internacional, onde existem restrições severas em relação à emanação radioativa. Portanto, é de interesse conhecer a concentração de Rn no ar contido nos solos da região, na busca de subsídios à análise de risco para a saúde das pessoas que vivem naquela área. 


\section{2 Área, materiais e métodos}

\subsection{Localização da área de estudo}

O Maciço Sienítico Piquiri localiza-se no centro-Leste do Estado Rio Grande do Sul, aflorando na zona Leste da Folha Capané (SH.22-Y-A-III-3) e no Oeste da Folha Passo das Canas (SH.22-Y-A-III-4). A distância entre o corpo e a capital do Estado é de aproximadamente $180 \mathrm{~km}$. 0 acesso desde Porto Alegre pode ser feito pela rodovia BR290, até Vila Piquiri, no Município de Cachoeira do Sul, tomando-se a direção para Encruzilhada do Sul (Fig. 1), onde ocorre o lado Sul da intrusão.

O Escudo Sul-rio-grandense é o resultado de processos de geração e deformação de crosta continental que aconteceram nos ciclos Orogênicos Transamazônico e Brasiliano (Hartmann et al., 2007). Este último está marcado por magmatismo de arco e pós-colisional com idades entre $760 \mathrm{Ma}$ e $550 \mathrm{Ma}$ (Bitencourt \& Nardi, 2000). O Batólito Pelotas é uma unidade que faz parte do Ciclo Brasiliano e representa um período de retrabalhamento crustal (Hartmann et al., op. cit.). Esta unidade está constituída por seis suítes graníticas, de composição variável e uma suíte sienítica com idades entre 650 Ma e 550 Ma (Philipp et al., 2002; Hartmann et al., op. cit.).

A suíte sienítica do Batólito Pelotas é representada pelo Maciço Sienítico Piquiri, que é uma intrusão semicircular com área aproximada de 150 $\mathrm{km}^{2}$ e com idades de $611 \mathrm{Ma} \pm 3$ Ma obtidas pelo método de $\mathrm{Pb}-\mathrm{Pb}$ em grãos de zircão (Philipp et al., 2002). Esta intrusão possivelmente foi formada a partir de magmatismo sienítico de afinidade shoshonítica, sofrendo processos de mistura com magmas lamprofíricos (Stabel et al., 2001; Nardi et al., 2007, 2008). O Maciço Sienítico Piquiri é intrudido por granitos de grão grosso do Complexo Encruzilhada, os quais se projetam, em planta, para o interior do sienito no Sudeste, conferindo-lhe a forma de ferradura (Jost et al., 1985; Philipp et al., op. cit.; Nardi et al., 2007). As rochas encaixantes do corpo principal do Maciço Sienítico Piquiri apresentam composição, gênese e idades variadas. No Leste, Nordeste e, em parte, ao Norte, as rochas encaixantes são blastomilonitos derivados de gnaisses estrutural e texturalmente variados e, localizadamente, de granitos granatíferos. No Noroeste ocorrem xistos pelíticos e quartzitos do Grupo Cerro dos Madeiras. No Oeste e Sudoeste a intrusão sienítica apresenta contato por falha com ritmitos do Membro Mangueirão (Proterozoico Superior), que são parcialmente recobertos por conglomerados eopaleozoicos a permocarboníferos.

o Maciço Sienítico Piquiri é representado por quatro tipos litológicos principais que apresentam contatos internos gradativos (Fig. 2). No interior da intrusão (Fácies Principal), que constitui a maior parte do corpo sienítico, predomina o feldspato-alcalino sienito de textura equigranular média a grossa, entanto a região correspondente à borda ou margem resfriada (Fácies da Borda), que

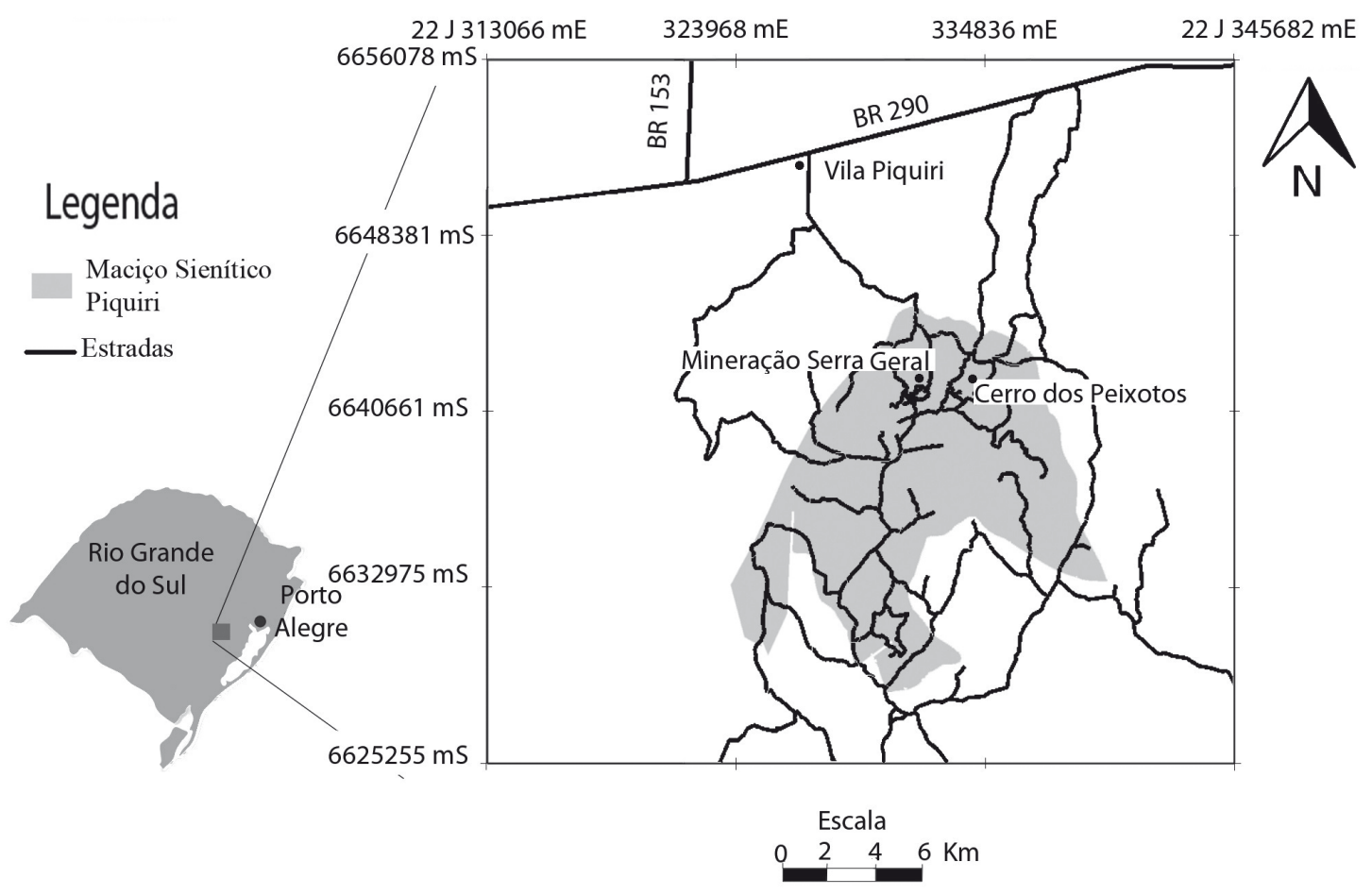

Figura 1. Localização da área de estudo. 


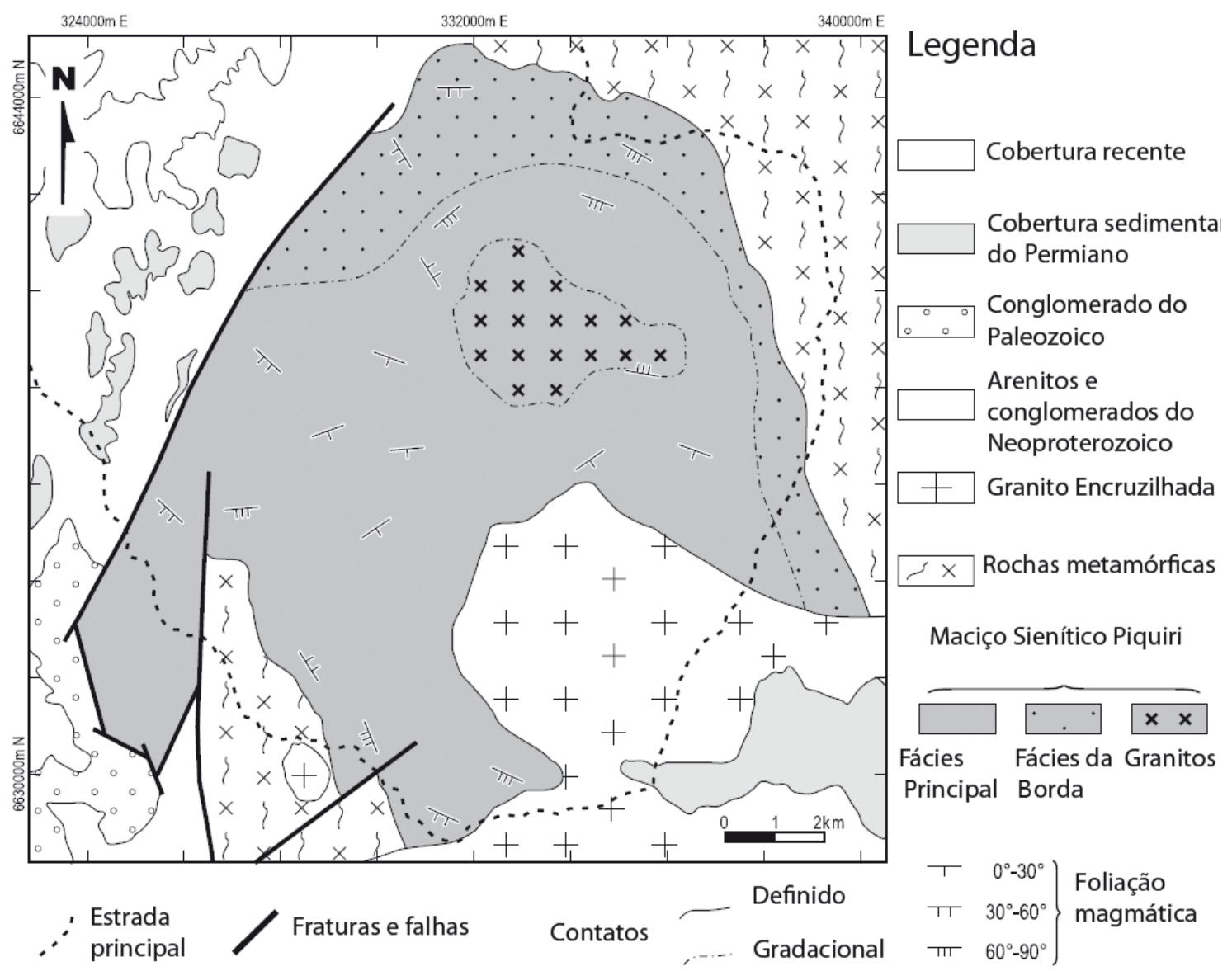

Figura 2. Mapa geológico do Maciço Sienítico Piquiri (Modificado de Nardi et al., 2008).

abrange a porção mais externa do corpo, é composta por sienitos a quartzo monzonitos de textura equigranular fina a média, localizadamente porfirítica. 0 terceiro tipo lotológico é constituido por flogopita-diopsídio sienitos, que mostram características de mistura com feldspato-alcalino sienitos, enquanto o quarto tipo, localizado no centro da intrusão, varia entre sienogranitos e feldspato-alcalino granitos, representando a etapa final da cristalização, onde são frequentes autólitos de sienito (Nardi et al., 2007).

Os latossolos e litossolos no Maciço Sienítico Piquiri possuem cor vermelha amarelada e são, em geral, rasos e bem drenados, com espessuras variáveis entre poucos centímetros até poucos metros e horizontes mal definidos. Nas áreas mais elevadas da região, onde a espessura de solos pode ser reduzida, afloramentos de rocha são encontrados misturados com areias feldspáticas a quartzo-fedspáticas grossas, com conteúdo menor de óxidos e hidróxidos de ferro e alumínio. Nas áreas baixas, a espessura dos solos é maior, bem como o conteúdo de óxidos e hidróxidos de ferro e alumínio, aos quais se soma matéria orgânica, localizadamente abundante.

\subsection{Materiais e métodos}

A região do Maciço Sienítico Piquiri foi dividida em quadrículas de $2 \mathrm{~km}$ de lado definindo-se pontos de amostragem no centro (Fig. 3). As medidas de radiação gama foram feitas in situ com tempo de medida de $120 \mathrm{~s}$, usando o equipamento gama espectrômetro RS-125 que contém um detector de um cristal de $103 \mathrm{~cm}^{3}$ de NaI (Tl), com capacidade de ler taxa de dose e contagens totais por segundo (cps) de K, U e Th. Este equipamento discrimina a contagem total e a energia de 2,62 $\mathrm{MeV}$ pertencente ao pico do ${ }^{208} \mathrm{Tl}$ (na determinação de equivalente tório, eTh), a energia de $1,76 \mathrm{MeV}$ do ${ }^{214} \mathrm{Bi}$ (na determinação de equivalente urânio, $\mathrm{eU}$ ) e a energia de $1,46 \mathrm{MeV}$ do ${ }^{40} \mathrm{~K}$ (potássio). Não obstante, este equipamento mede uma faixa de energia para cada pico, isto é, 2,42 - 2,82 MeV, 1,66 - 1,86 MeV e 1,36 - 1,56 MeV, respectivamente. As concentrações de cada radionuclídeo principal são estimadas, assumindo um equilíbrio radioativo entre esse e seus descendentes radioativos (Milsom, 2003).

Foram selecionados 18 pontos da quadrícula para realizar medidas de radônio e torônio in situ em solos (Fig. 4). Estes pontos foram distribuídos em função dos resultados de gamaespectrome- 
tria. Para as medidas das concentrações de ${ }^{222} \mathrm{Rn}$ $\mathrm{e}^{220} \mathrm{Rn}$ foi usado o equipamento AlphaGUARD PQ 2600. Este equipamento conta com uma unidade para determinar radônio no ar do solo, que consiste de uma vara de perfuração com uma ponta intercambiável e sonda capilar conectada a uma bomba de sucção. Foram feitas perfurações de aproximadamente $80 \mathrm{~cm}$ com a vara de perfuração, que após é alçada $3 \mathrm{~cm}$ a $5 \mathrm{~cm}$, sendo inserida a sonda capilar até empurrar a ponta intercambiável para liberar a entrada de ar. Com a bomba e o equipamento AlphaGUARD conectados em série, o gás do solo é bombeado através da sonda capilar e levado à câmara de ionização, onde é determinada a média da concentração total de radônio (Fig. 4). Com a finalidade de determinar a concentração de ${ }^{222} \mathrm{Rn}$, a câmara de ionização é fechada e desliga-se a bomba de sucção por aproximadamente $10 \mathrm{~min}$, tempo necessário para o ${ }^{220} \mathrm{Rn}$ decair, ou até chegar a um valor de concentração de Rn estável, onde a média dos valores obtidos neste tempo representa a concentração de ${ }^{222} \mathrm{Rn}$. Desta maneira, o ${ }^{220} \mathrm{Rn}$ é determinado a partir da diferença entre $\mathrm{Rn}$ total e o ${ }^{222} \mathrm{Rn}$.

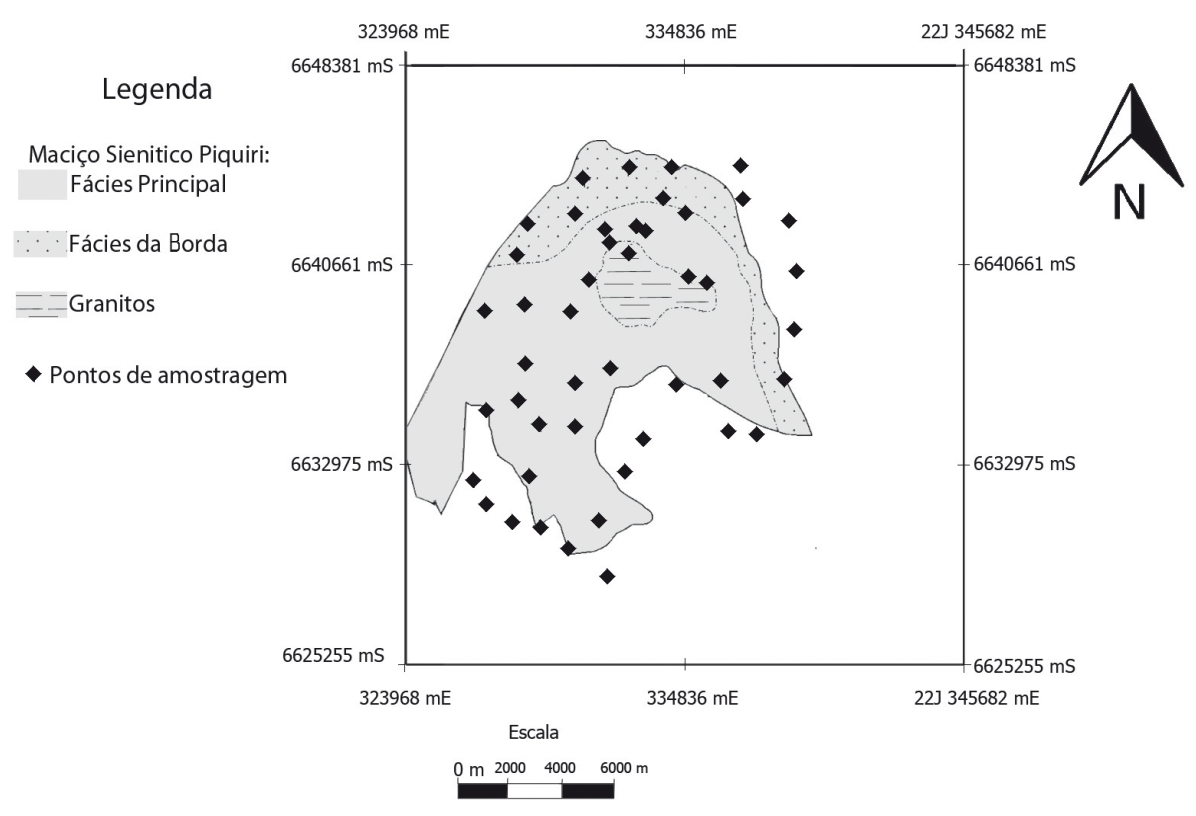

Figura 3. Localização dos pontos onde foram feitas as medidas de radiação gama.

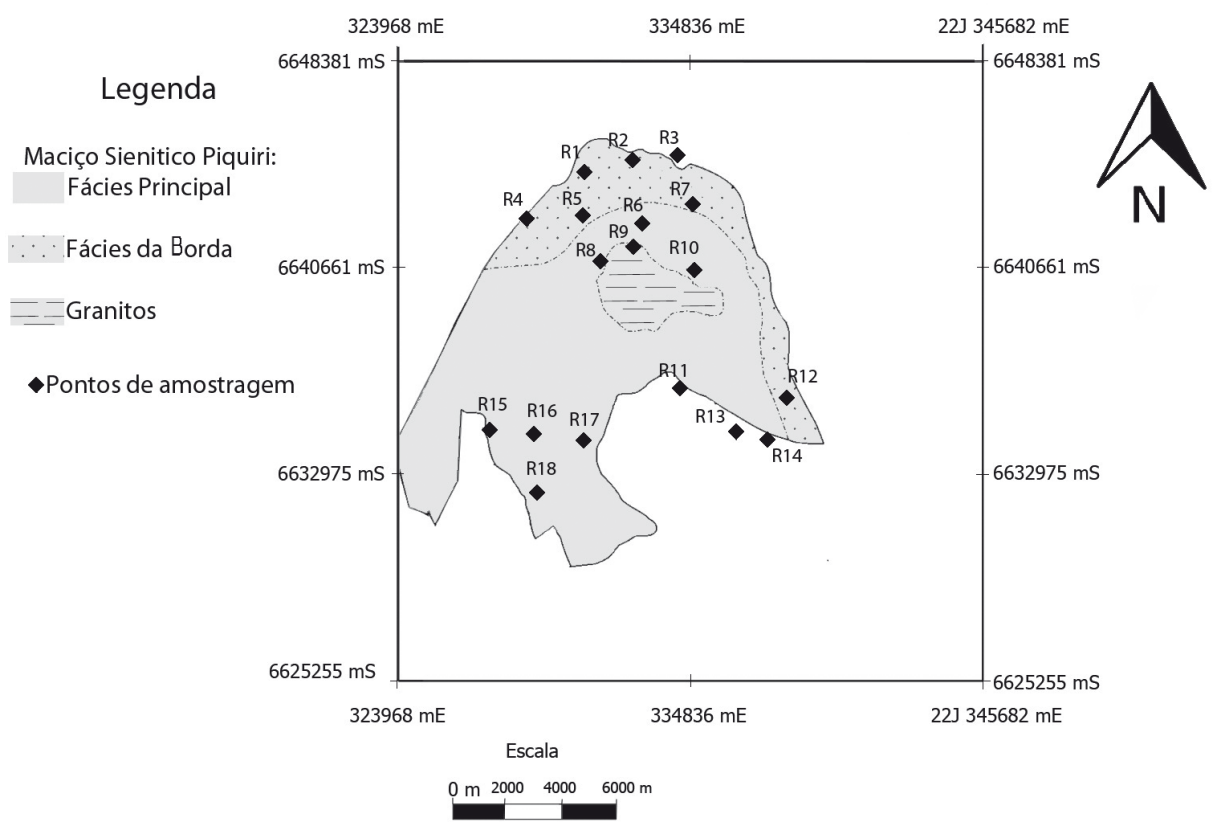

Figura 4. Localização dos pontos onde foram feitas as medidas de Rn com AlphaGUARD. 
Foi realizado estudo estatístico usando o programa Surfer versão 8.02 de Golden Software para determinar a distribuição espacial das medidas de contagem por segundo (cps), taxa de dose (Dr), concentração de $\mathrm{K}(\%)$ e concentrações de equivalente tório (eTh) e equivalente urânio (eU) em ppm obtidas com o gamaespectrômetro. 0 método usado para a grade geoestatística foi o de Krigagem, que produz um mapa de tendência que depende dos valores iniciais. Além disso, foi feita uma análise de estatística descritiva para os resultados de radiometria e de concentrações de radônio nos solos, obtendo-se os valores máximo, mínimo, média e desvio padrão, para determinar a dispersão e intervalo dos dados.

\section{Resultados}

\subsection{Gamaespectrometria}

Foram realizadas 62 medidas gamaespectrométricas, distribuídas em 42 pontos apresentados nas tabelas 1 e 2 . Os resultados demonstraram uma grande variação de valores, produto das características próprias de cada litologia aflorante e dos solos originados. Os valores estão compreendidos entre 130 e $1045 \mathrm{cps}$, taxa de dose entre 28,9 $\mathrm{nSv} / \mathrm{h}$ e $424,6 \mathrm{nSv} / \mathrm{h}$, concentrações de K entre 0,5 $\%$ e $8,3 \%$, concentrações de eU entre 0,8 ppm e 25,8 ppm, e concentrações de eTh entre 3,0 ppm e 99,2 ppm. A Fácies Principal do Maciço Sienítico Piquiri apresenta valores médios de radiação gama de 550 cps e $230 \mathrm{nSv} / \mathrm{h}$, e concentrações médias de $5 \%, 6$ ppm e 40 ppm de $\mathrm{K}$, eU e eTh, respectivamente. Entretanto, a Fácies da Borda apresenta valores médios de radiação gama de $300 \mathrm{cps,}$ $100 \mathrm{nSv} / \mathrm{h}$, e concentrações médias de $3 \%$ de $\mathrm{K}$, $5 \mathrm{ppm}$ de eU e $20 \mathrm{ppm}$ de eTh. A área delimitada pelo sienogranito do MSP apresenta valores médios de radiação gama de $460 \mathrm{cps}$ e $210 \mathrm{nSv} / \mathrm{h}$, e concentrações médias de $5 \%$ de K, 6 ppm de eU e $34 \mathrm{ppm}$ de eTh. Desta forma, também foram feitas medidas espectroradiométricas nos solos desenvolvidos sobre as litologias presentes nos contatos Nordeste (rochas metamórficas) e Sudeste (Granito de Encruzilhada); determinando-se valores médios de 350 cps, $150 \mathrm{nSv} / \mathrm{h}, 3 \%$ de $\mathrm{K}, 5 \mathrm{ppm}$ de eU e $21 \mathrm{ppm}$ de eTh nos solos sobre rochas metamórficas; e $210 \mathrm{cps}, 90 \mathrm{nSv} / \mathrm{h}, 2 \%$ de K, 4 ppm de eU e 11 ppm de eTh nos solos sobre o Granito de Encruzilhada.

As figuras 5 a 9 representam mapas de distribuição de cada parâmetro analisado. A área do Maciço Sienítico Piquiri destaca-se pelos elevados valores de radiação gama, em contraste com o Granito Encruzilhada, a Sudeste. Não obstante, os valores de radiação gama deste corpo granítico são superiores às demais litologias que circundam o sienito.

O setor Norte do Maciço Sienítico Piquiri registra maiores valores de radiação gama (Figs. 5 e 6). Neste setor, a espessura de solos é menor, resultando numa área aflorante maior de rocha sã.

O mapa de distribuição de K (Fig. 7) discrimina nitidamente as mudanças litológicas da área, com valores relativamente baixos próximos aos contatos Norte, Sul e Oeste, e um intervalo intermediário no Granito Encruzilhada, a Sudeste. No âmbito do Maciço Sienítico Piquiri, o K destaca a Fácies Principal do sienito, com valores elevados de $\mathrm{K}$, atingindo o ápice na área das pedreiras, onde a espessura do solo é menor. É interessante ressaltar que a margem resfriada da intrusão (Fácies da Borda) apresenta um valor médio de $\mathrm{K}$ menor do que a Fácies Principal. 0 mapa de distribuição de K parece ser uma boa aproximação para delimitar contatos litológicos e pequenas mudanças litológicas (IAEA, 2003) do Maciço Sienítico Piquiri, porque este elemento está relacionado com o feldspato potássico, que é a fase mineral dominante no sienito. Não obstante, deve-se levar em consideração que as características dos solos e das rochas intemperizadas podem interferir nos resultados.

0 eTh (Fig. 8) exibe uma variação similar ao $\mathrm{K}$, havendo um bom contraste com as litologias adjacentes, em razão da presença de minerais radioativos no sienito, como o zircão e titanita, dentre outros. Dentre as rochas que estão em contato com o Maciço Sienítico Piquiri, o Granito Encruzilhada é a que apresenta maior concentração de eTh. No interior da intrusão sienítica, a Fácies de Borda mostra as menores concentrações de eTh, à exceção de um ponto no Noroeste que pode sofrer interferência pelo uso do sienito como material de construção nas proximidades do ponto de amostragem.

Dentre os mapas de distribuição estatística, o do eU (Fig. 9) exibe menos correlação com as litologias, registrando os maiores valores no Nordeste do Maciço Sienítico Piquiri, em área correspondente à Fácies Principal, o que pode ter relação com a pequena espessura de solos. A zona a Oeste e Sudoeste da intrusão e a zona da Fácies da Borda apresentam, em geral, baixas concentrações de eU. Assim, o eU não é um bom marcador litológico, no caso em foco, notando-se que os sienogranitos não apresentam diferenças na concentração de eU com a Fácies Principal do sienito. 
Tabela 1. Resultados de radiometria obtidos com uso do gama-espectrômetro RS-125. P01 a P34.

\begin{tabular}{|c|c|c|c|c|c|c|c|}
\hline & \multicolumn{2}{|c|}{ Coordenadas } & \multicolumn{5}{|c|}{ Resultados Espectroradiométricos } \\
\hline Ponto & $\mathrm{mE} 22 \mathrm{~J}$ & $\mathrm{mS}$ & Cps & $\operatorname{Dr}(\mathrm{nSv} / \mathrm{h})$ & $\mathrm{K}(\%)$ & $\mathrm{eU}(\mathrm{ppm})$ & eTh (ppm) \\
\hline P01 & 332717 & 6644335 & 180 & 78,2 & 1,6 & 3,1 & 10 \\
\hline $\mathrm{P} 02$ & 334356 & 6644446 & 185 & 77 & 1,1 & 3,7 & 10,7 \\
\hline $\mathrm{P} 03$ & 334020 & 6643237 & 300 & 120,6 & 2,9 & 5,2 & 12,2 \\
\hline P04 & 334866 & 6642685 & 250 & 92,2 & 2,9 & 0,8 & 12,7 \\
\hline P05 & 334954 & 6640329 & 750 & 312,3 & 4 & 7,2 & 61,8 \\
\hline P06 & 335684 & 6640127 & 1000 & 424,6 & 5,8 & 14 & 73,8 \\
\hline P07 & 332666 & 6641165 & 400 & 189,4 & 3,9 & 4,8 & 29,3 \\
\hline P08 & 333072 & 6642072 & 550 & 254 & 5,1 & 5 & 43 \\
\hline P09 & 331235 & 6640206 & 400 & 194,8 & 5,4 & 3,6 & 26,5 \\
\hline P10 & 330683 & 6642621 & 800 & 401,3 & 4,7 & 25,8 & 48,3 \\
\hline P11 & 330922 & 6643943 & 180 & 67,8 & 1,7 & 1,2 & 9,9 \\
\hline P12 & 328838 & 6642300 & 160 & 45 & 0,9 & 1,3 & 6,9 \\
\hline P13 & 328364 & 6641057 & 250 & 87,2 & 3,3 & 1,5 & 7,8 \\
\hline P14 & 330463 & 6638854 & 370 & 166,4 & 4,4 & 2,8 & 24 \\
\hline P15 & 328669 & 6639166 & 480 & 207 & 4,9 & 3,1 & 33,9 \\
\hline P16 & 327131 & 6638935 & 530 & 210,8 & 4,3 & 3,4 & 37,1 \\
\hline P17 & 327131 & 6638935 & 760 & 351,2 & 6,1 & 4,7 & 68,8 \\
\hline P18 & 328753 & 6636895 & 350 & 132,9 & 3,6 & 2,6 & 18,1 \\
\hline P19 & 330575 & 6636128 & 500 & 223 & 4,3 & 6,1 & 35,4 \\
\hline P20 & 331994 & 6636699 & 500 & 242,4 & 6,1 & 8,6 & 27,5 \\
\hline P21 & 329157 & 6634445 & 460 & 219,9 & 3,8 & 5,3 & 38,4 \\
\hline P22 & 328437 & 6635473 & 560 & 231,2 & 4,7 & 4,9 & 38,2 \\
\hline P23 & 329026 & 6632477 & 550 & 235,6 & 4,5 & 4,9 & 40,4 \\
\hline P24 & 329241 & 6630595 & 370 & 140,1 & 4 & 3,2 & 17,3 \\
\hline P25 & 330677 & 6642693 & 720 & 320,0 & 5,8 & 5,8 & 78,8 \\
\hline P26 & 331773 & 6642046 & 684 & 243,6 & 6,3 & 8,2 & 43,4 \\
\hline P27 & 331787 & 6642044 & 827 & 340,4 & 8,3 & 16,6 & 52,4 \\
\hline P28 & 332622 & 6641152 & 516 & 227,5 & 5,9 & 8,1 & 39,6 \\
\hline P29 & 333455 & 6641981 & 1045 & 424,4 & 7,3 & 16,3 & 99,2 \\
\hline P30 & 331709 & 6628644 & 330 & 120,3 & 2,5 & 1,3 & 22,3 \\
\hline P31 & 330328 & 6629730 & 390 & 161,4 & 3 & 6,6 & 21,7 \\
\hline P32 & 328519 & 6630714 & 300 & 163,6 & 3,1 & 6 & 23 \\
\hline P33 & 328200 & 6630761 & 220 & 81,7 & 2 & 1,6 & 11,9 \\
\hline P34 & 327136 & 6631371 & 130 & 28,9 & 0,8 & 1 & 3 \\
\hline
\end{tabular}


Tabela 2. Resultados de radiometria obtidos com uso do gama- espectrômetro RS-125. P35 a P62.

\begin{tabular}{lccccccc}
\hline & \multicolumn{3}{c}{ Coordenadas } & \multicolumn{5}{c}{ Resultados Espectroradiométricos } \\
\hline Ponto & $\mathrm{mE} 22 \mathrm{~J}$ & $\mathrm{mS}$ & $\mathrm{Cps}$ & $\mathrm{Dr}(\mathrm{nSv} / \mathrm{h})$ & $\mathrm{K}(\%)$ & $\mathrm{eU}(\mathrm{ppm})$ & $\mathrm{eTh}(\mathrm{ppm})$ \\
\hline P35 & 326760 & 6632437 & 150 & 63,8 & 1,6 & 1,6 & 8,7 \\
P36 & 327313 & 6634977 & 480 & 223,8 & 4,5 & 5,8 & 35,4 \\
P37 & 329316 & 6634669 & 430 & 199,8 & 4,1 & 5,5 & 30,5 \\
P38 & 329304 & 6634669 & 450 & 271,0 & 5,4 & 6,8 & 43,1 \\
P39 & 330612 & 6634474 & 550 & 237,8 & 4,7 & 5,2 & 39,5 \\
P40 & 331305 & 6640011 & 500 & 216,8 & 4,1 & 4,9 & 36,7 \\
P41 & 331955 & 6641485 & 530 & 211,2 & 3,9 & 6 & 33,7 \\
P42 & 332008 & 6641917 & 630 & 300,8 & 5,7 & 6,9 & 50,6 \\
P43 & 331017 & 6642159 & 600 & 248,2 & 4,1 & 9,1 & 38,2 \\
P44 & 330693 & 6642561 & 250 & 77,8 & 1,8 & 1,3 & 12,4 \\
P45 & 336994 & 6644455 & 200 & 82,6 & 0,5 & 6,2 & 10,2 \\
P46 & 337018 & 6643285 & 200 & 78,8 & 1,1 & 2,8 & 13 \\
P47 & 338943 & 6642362 & 180 & 48,0 & 0,6 & 2,7 & 6,6 \\
P48 & 339238 & 6640383 & 260 & 114,0 & 2,3 & 7,2 & 9,6 \\
P49 & 339101 & 6638160 & 290 & 116,7 & 3,3 & 6,7 & 6,2 \\
P50 & 338652 & 6636244 & 330 & 149,1 & 2,8 & 5,9 & 20 \\
P51 & 337708 & 6634165 & 330 & 117,3 & 1,7 & 6,1 & 15,5 \\
P52 & 336330 & 6636209 & 370 & 126,6 & 3 & 6,4 & 11,1 \\
P53 & 336530 & 6634334 & 330 & 139,4 & 3,6 & 4,7 & 15,7 \\
P54 & 334510 & 6636006 & 400 & 166,2 & 5 & 3,1 & 20,6 \\
P55 & 333342 & 6633995 & 500 & 244,0 & 4,9 & 7,5 & 36,1 \\
P56 & 332573 & 6632665 & 360 & 159,7 & 2,9 & 8,2 & 18,6 \\
P57 & 331501 & 6630810 & 620 & 275,5 & 4,8 & 5,6 & 49,8 \\
P58 & 331297 & 6644080 & 170 & 47,4 & 1 & 1,8 & 5,9 \\
P59 & 331271 & 6644100 & 230 & 95,1 & 2,8 & 3 & 9,4 \\
P60 & 331166 & 6644016 & 180 & 65,4 & 2 & 1,6 & 7 \\
P61 & 330837 & 6644031 & 300 & 151,9 & 4,6 & 4,4 & 15,3 \\
P62 & 330887 & 6643962 & 200 & 85,7 & 2,6 & 1,1 & 11,5 \\
\hline & & & & & & & \\
\end{tabular}

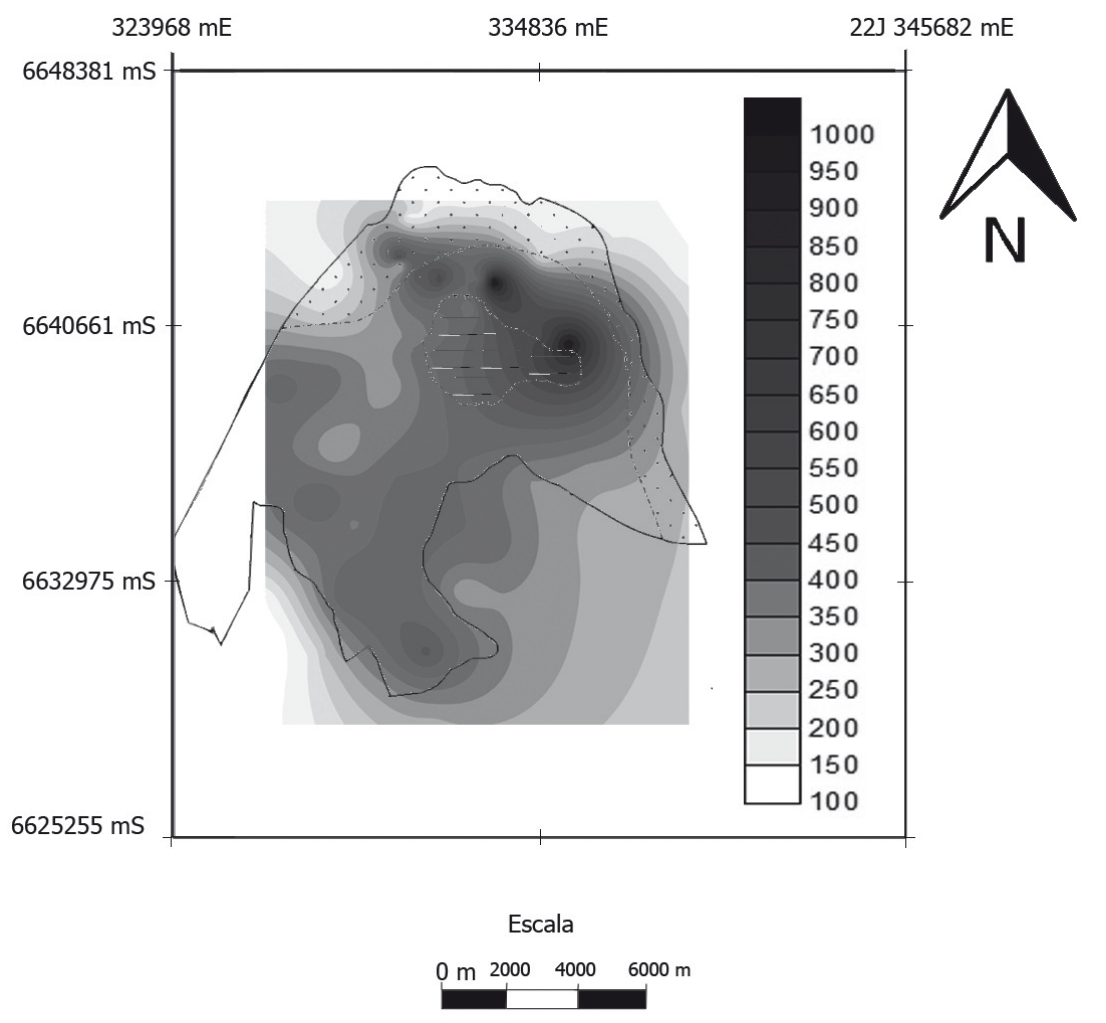

Figura 5. Mapa radiométrico de distribuição de contagens por s (cps). 


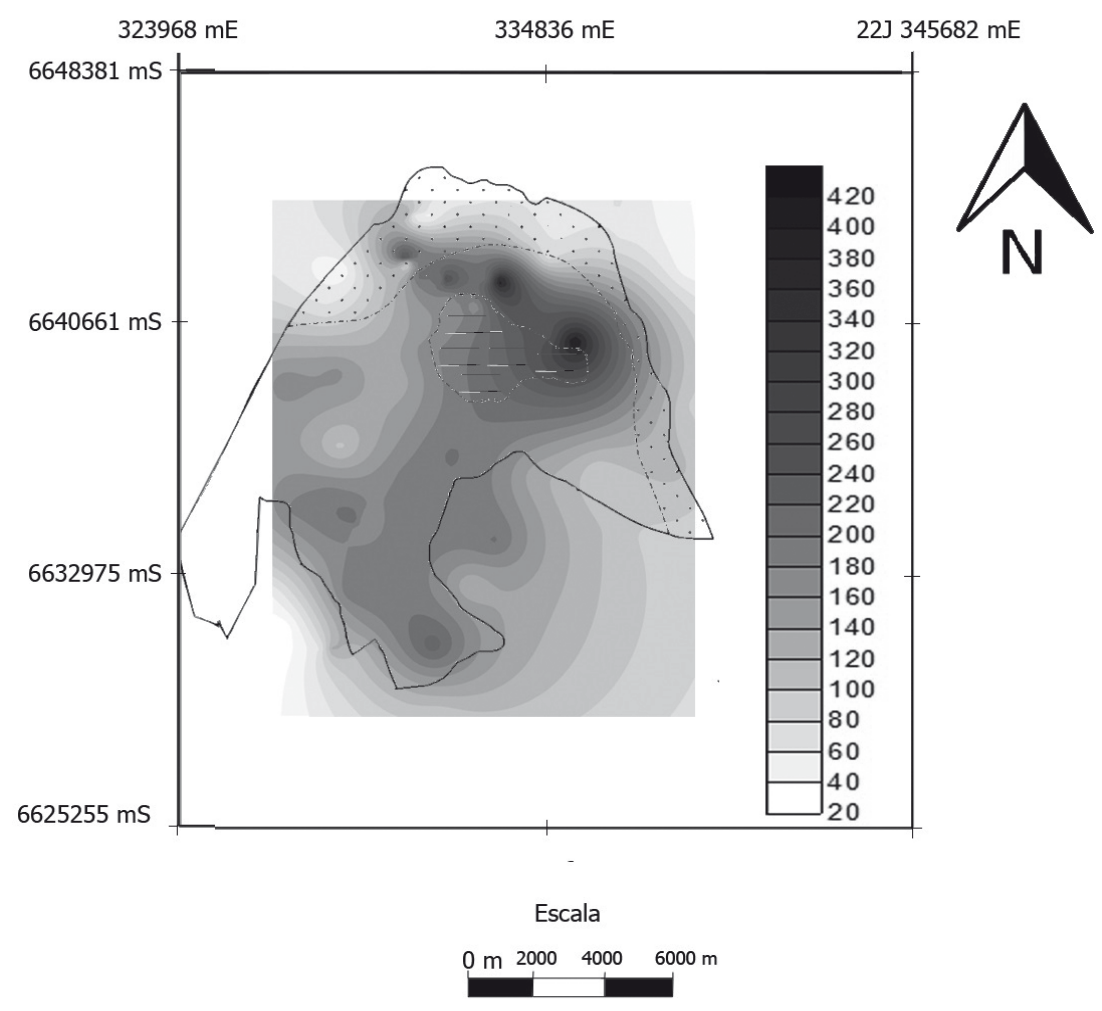

Figura 6. Mapa de distribuição de taxa de dose (Dr) de radiação gama em nSv/h.

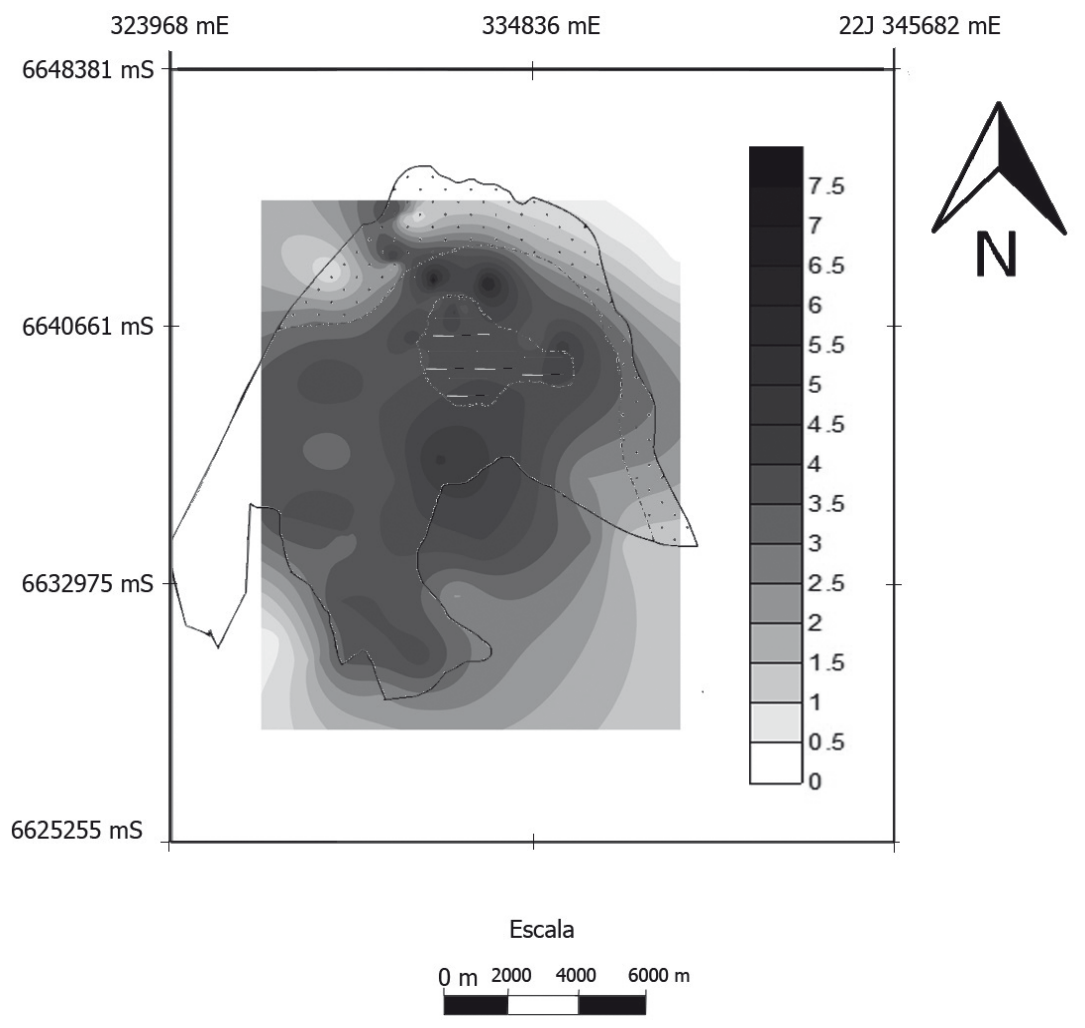

Figura 7. Mapa de distribuição da concentração de potássio em porcentagem. 


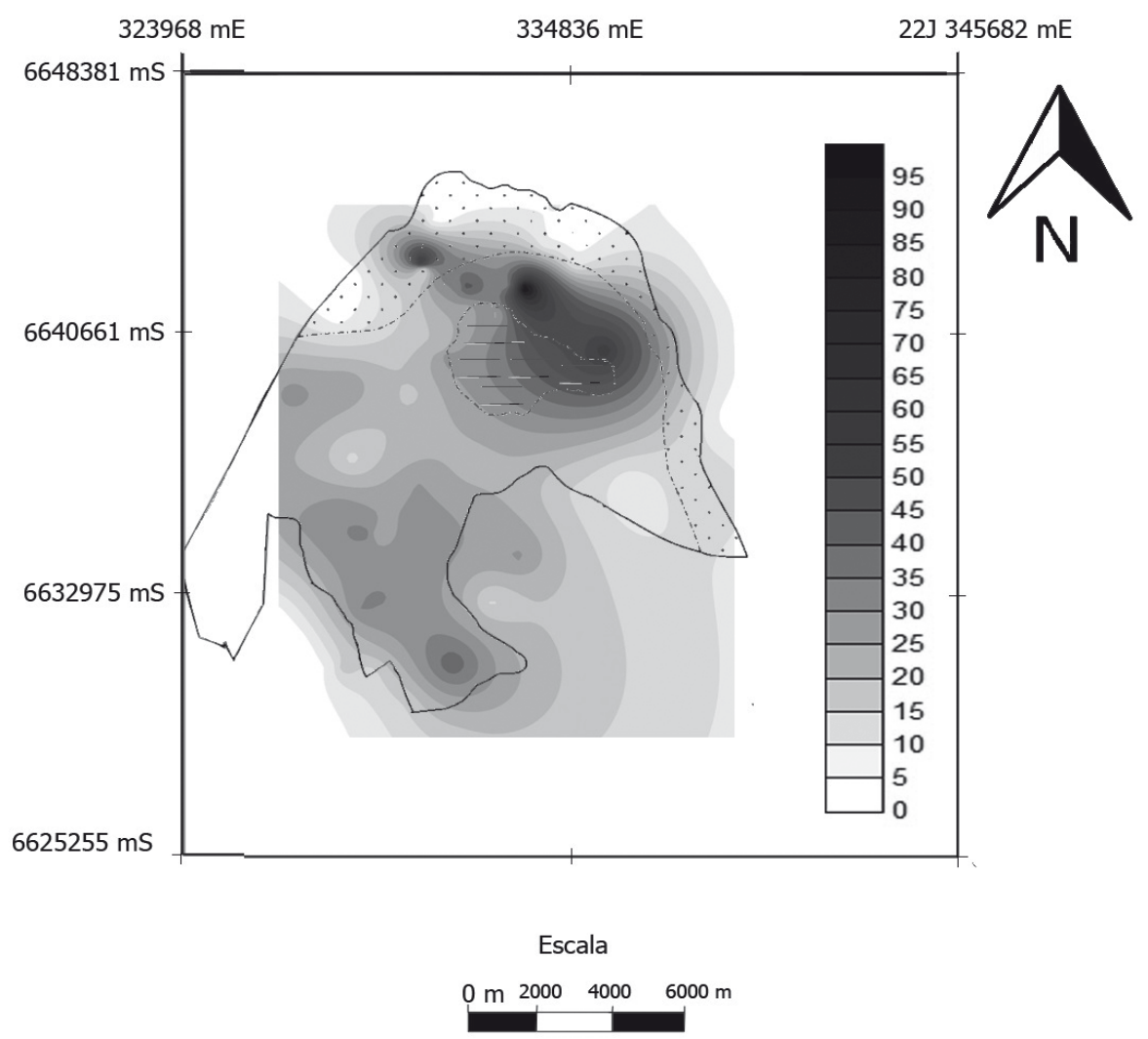

Figura 8. Mapa de distribuição da concentração de equivalente tório em ppm.

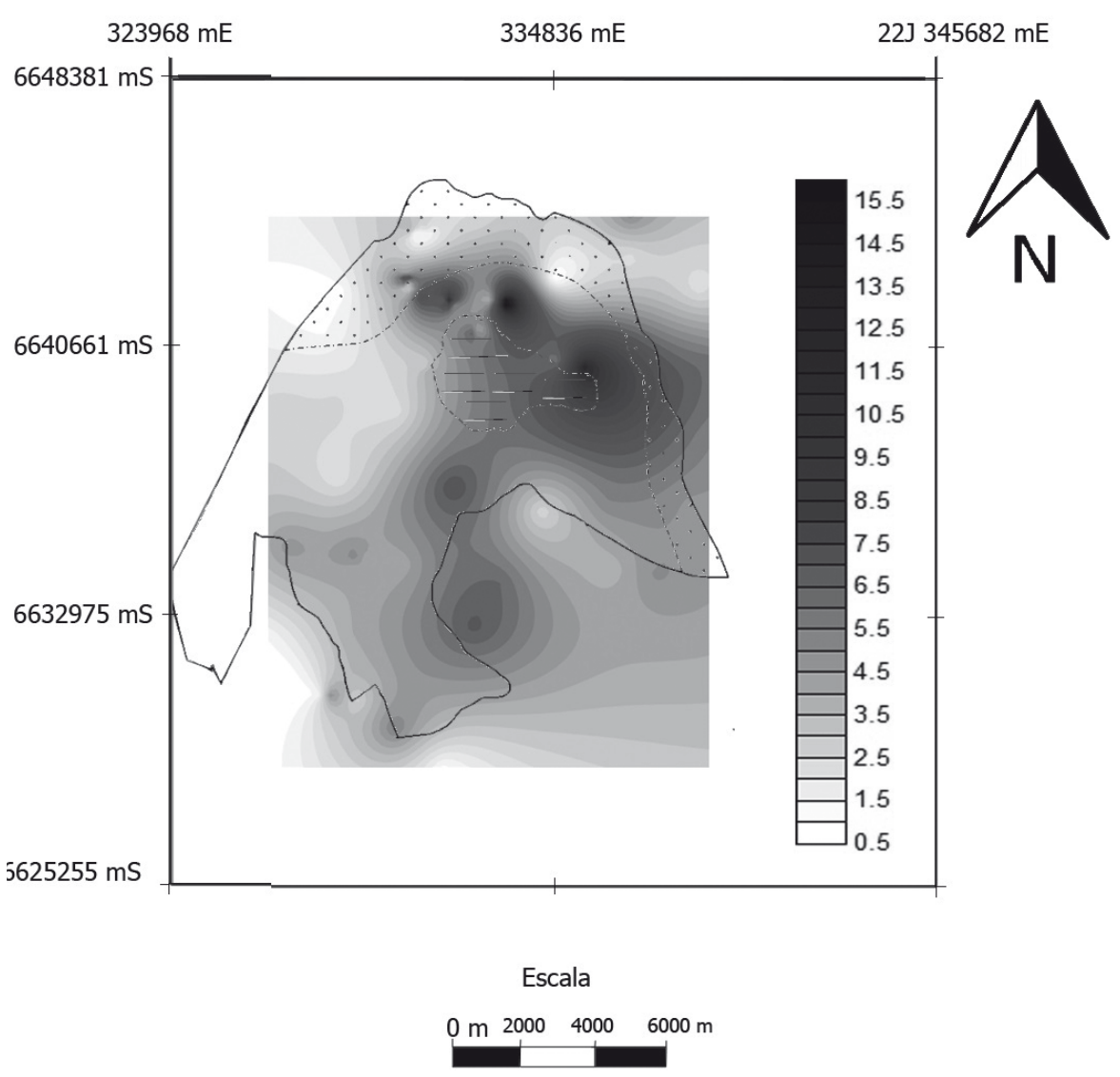

Figura 9. Mapa de distribuição da concentração de equivalente urânio em ppm. 


\subsection{Concentração de radônio}

Os valores de Rn total, ${ }^{220} \mathrm{Rn},{ }^{222} \mathrm{Rn}$ e umidade em cada ponto estão registrados na tabela 3. Os resultados de concentração deste elemento, em geral, apresentam uma forte dispersão, refletida no desvio padrão da média para cada ponto, e uma igualmente forte variação entre os pontos medidos na mesma litologia. 0 ponto R1, por exemplo, apresenta umidade de $62 \% \pm 2 \%$, o que pode interferir no fluxo de radônio, diminuindo a concentração do gás no ar do solo (Manohar et al., 2013).

Os pontos R15, R16, R17 e R18, pertencentes ao setor sul do Maciço Sienítico Piquiri, apresentam baixa concentração de ${ }^{222} \mathrm{Rn}$ em relação ao ${ }^{220} \mathrm{Rn}$, refletindo uma dependência das concentrações de eU que são menores ao Sul da Fácies Principal do que no Norte (Fig. 9).

0 ponto R18 registra a maior concentração de Rn total dos pontos amostrados, correspondendo a $560 \mathrm{kBq} / \mathrm{m}^{3} \pm 50 \mathrm{kBq} / \mathrm{m}^{3}$. Neste ponto, a concentração de ${ }^{220} \mathrm{Rn}$ representa a quase totalidade da concentração total de Rn. 0 ponto R12, perten- cente à Fácies da Borda, possui baixa concentração de eU e, correspondentemente, um valor baixo de ${ }^{222} \mathrm{Rn}$. Situação similar é registrada no ponto R6, que pertence à Fácies Principal da intrusão.

O ponto R3 é o único ponto analisado pertencente às rochas metamórficas da área Norte da intrusão sienítica. No local, foi verificado que os solos apresentam baixa concentração de Rn em relação aos solos do Maciço Sienítico Piquiri. Os solos do Granito Encruzilhada, na região estudada, possuem concentração de Rn total compreendida entre $70 \mathrm{kBq} / \mathrm{m}^{3}$ e $190 \mathrm{kBq} / \mathrm{m}^{3}$.

Na figura 10 estão representados os valores médios de concentração de Rn com relação à litologia local, desconsiderando-se os pontos com concentração de Rn total menor que o limite de detecção do equipamento. A zona de maior concentração de Rn situa-se na Fácies Principal do Maciço Sienítico Piquiri. No setor Sul (Fácies Principal-Sul) e no setor norte (Fácies Principal-Norte) registram-se as maiores concentrações de Rn total, contrastando pela contribuição expressiva de ${ }^{220} \mathrm{Rn}$ na zona meridional.

Tabela 3. Resultados de Rn total, ${ }^{220} \mathrm{Rn},{ }^{222} \mathrm{Rn}$ e umidade em cada ponto amostrado, incluindo a sua litologia. N.D. - não detectado.

\begin{tabular}{cccccc}
\hline Ponto & $\mathrm{Rn} \mathrm{Total}\left(\mathrm{kBq} / \mathrm{m}^{3}\right)$ & ${ }^{220} \mathrm{Rn}\left(\mathrm{kBq} / \mathrm{m}^{3}\right)$ & ${ }^{222} \mathrm{Rn}\left(\mathrm{kBq} / \mathrm{m}^{3}\right)$ & Umidade $(\%)$ & Litologia \\
\hline R1 & $<1$ & N.D. & $<1$ & $62 \pm 2$ & Fáceis da Borda \\
R2 & $110 \pm 10$ & $20 \pm 10$ & $88 \pm 8$ & $51 \pm 5$ & Fáceis da Borda \\
R3 & $55 \pm 7$ & $37 \pm 9$ & $18 \pm 6$ & $44 \pm 6$ & Rochas metamórficas \\
R4 & $180 \pm 20$ & $130 \pm 20$ & $50 \pm 20$ & $37 \pm 1$ & Fáceis da Borda \\
R5 & $40 \pm 10$ & $30 \pm 10$ & $5 \pm 3$ & $54 \pm 1$ & Fáceis da Borda \\
R6 & $210 \pm 20$ & $210 \pm 20$ & $<3$ & $37 \pm 1$ & Fáceis Principal-Norte \\
R7 & $90 \pm 20$ & $40 \pm 20$ & $52 \pm 8$ & $36 \pm 2$ & Fáceis da Borda \\
R8 & $100 \pm 10$ & $10 \pm 20$ & $90 \pm 20$ & $46 \pm 2$ & Fáceis Principal-Norte \\
R9 & $<4$ & $<2$ & $<3$ & $32 \pm 1$ & sienogranito \\
R10 & $510 \pm 80$ & $110 \pm 90$ & $400 \pm 40$ & $35 \pm 2$ & Fáceis Principal-Norte \\
R11 & $190 \pm 30$ & $140 \pm 30$ & $50 \pm 10$ & $32 \pm 2$ & Granito Encruzilhada \\
R12 & $70 \pm 20$ & $70 \pm 20$ & $<2$ & $31 \pm 2$ & Fáceis da Borda \\
R13 & $<1$ & $\mathrm{~N} . \mathrm{D}$. & $<1$ & $28 \pm 1$ & Granito Encruzilhada \\
R14 & $70 \pm 10$ & $40 \pm 20$ & $30 \pm 10$ & $29 \pm 1$ & Granito Encruzilhada \\
R15 & $210 \pm 40$ & $210 \pm 40$ & $<2$ & $48 \pm 5$ & Fáceis Principal-Sul \\
R16 & $200 \pm 20$ & $200 \pm 20$ & $<3$ & $33 \pm 2$ & Fáceis Principal-Sul \\
R17 & $70 \pm 10$ & $70 \pm 10$ & $<1$ & $34 \pm 2$ & Fáceis Principal-Sul \\
R18 & $560 \pm 50$ & $550 \pm 50$ & $8 \pm 8$ & $52 \pm 4$ & Fáceis Principal-Sul \\
\hline
\end{tabular}




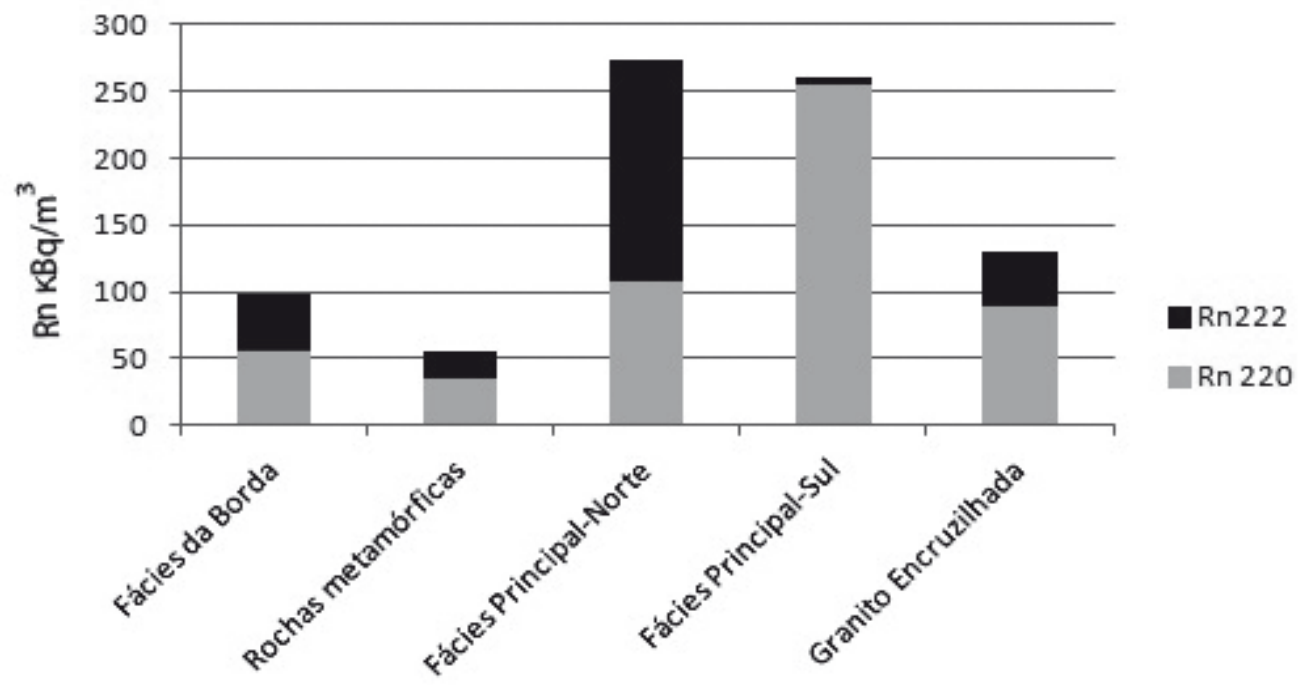

Figura 10. Média de concentrações de ${ }^{220} \mathrm{Rn}$ e ${ }^{222} \mathrm{Rn}$ na Fácies Principal e da Borda do Maciço Sienítico Piquiri, solos de rochas metamórficas do contato Norte e solos do Granito Encruzilhada do contato Sudeste.

\section{Discussão dos resultados}

As concentrações de $\mathrm{K}$, eU e eTh obtidas por gamaespectrometria no Maciço Sienítico Piquiri mostram-se comparáveis com os resultados obtidos por Nardi et al. $(2007,2008)$ que utilizaram os métodos de Espectrometria de Emissão Óptica com Plasma Indutivamente Acoplado (ICP-OES) e Espectrometria de Massa com Plasma Indutivamente Acoplado (ICP-MS). As concentrações variam entre 2 - 39 ppm no caso do U, e 9 - 181 ppm para o Th. $\mathrm{O}$ mapa de distribuição de K obtido pelo método radiométrico serviu para delimitar com relativa precisão contatos litológicos do Maciço Sienítico Piquiri, possibilitando utilizar esta ferramenta em áreas com poucos afloramentos.

A análise dos resultados de $\mathrm{Rn}$ mostrou o registro de pontos com concentração de Rn total menor que $5 \mathrm{kBq} / \mathrm{m}^{3}$, que sugerem "falsos negativos", como demonstraram Kitto \& Green (2008) e Fianco et al. (2012) ao estudar solos argilosos com baixa permeabilidade, que inibem a migração do Rn para a superfície. Os resultados de concentração de Rn obtidos neste estudo não apresentam uma boa correlação com os resultados de umidade; portanto, as baixas concentrações de Rn obtidas nos pontos R1, R9 e R13, podem estar relacionadas a outras características destes solos, como a porosidade. Somam-se a isto as condições do solo no local, tendo a sonda capilar do equipamento atingido zonas próximas às do nível d'água, onde o fluxo de Rn está controlado pela direção de fluxo da água, impedindo que o gás migre verticalmente para a superfície, como determinou Rebelo et al. (2003).
Na figura 11 são representados os valores de Rn total vs. eTh e Rn total vs. eU no corpo sienítico, mostrando que a correlação de concentração de $\mathrm{Rn}$ com resultados radiométricos não é uma correlação linear simples, porque a emanação de Rn está controlada pelo fluxo do gás no solo, podendo ser afetada por diversos fatores. Smethurst et al. (2008) compararam as concentrações de Rn no interior de casas com o eU obtido por métodos aero-radiométricos na região de Oslofjord (Noruega), encontrando que as relações entre as concentrações de Rn e as concentrações de eU não são lineares. Não obstante, é observado que existe correlação direta do Rn nos solos com as concentrações de eU e eTh. Por outro lado, representações gráficas mostraram que a dispersão de valores é ainda maior entre as concentrações de ${ }^{220} \mathrm{Rn}$ e eTh e de ${ }^{222} \mathrm{Rn}$ e eU, mesmo sabendo-se que os isótopos ${ }^{220} \mathrm{Rn}$ e ${ }^{222} \mathrm{Rn}$ são produtos do decaimento radioativo do ${ }^{232} \mathrm{Th}$ e do ${ }^{238} \mathrm{U}$, respectivamente (Milsom, 2003).

A figura 12 mostra os principais lineamentos tectônicos no Maciço Sienítico do Piquiri e a localização dos pontos de análise de Rn. Observa-se que os pontos R1, R2, R5, R7 e R17 estão em área de baixa densidade de fraturas, o que pode inibir a migração de radônio para a superfície. Pereira (2009) realizou perfis com espaçamento de $20 \mathrm{~m}$ em área da Cidade de São Paulo (SP), visando localizar estruturas tectônicas e mapear aquíferos fraturados a partir da emanação natural de radônio. A metodologia mostrou-se eficiente e demonstrou que existem relações entre anomalias de $\mathrm{Rn}$ com anomalias geoelétricas e que o uso desta técnica permite uma mais segura locação de poços de água 
subterrânea.

Não foram encontradas correlações significativas entre as concentrações de Rn e os valores de radiação gama. Entretanto, descartando os pontos situados em áreas com baixa densidade de fraturas, a correlação de Rn total com o eTh melhora sensivelmente, apesar do mesmo não acontecer no caso do eU (Fig. 13).

A baixa correlação entre as concentrações de Rn total e eU e eTh, no presente caso, pode ser atribuída a diversos fatores: (i) a concentração de Rn no solo, que pode oscilar ao longo do dia, como decorrência de fatores climáticos e, inclusive, da umidade relativa do solo, como descrito por Pascale et al. (2014); (ii) variações na densidade de fraturas, que podem favorecer ou limitar a migração do radônio até a superfície; (iii) distribuição heterogênea de minerais radioativos na rocha e nos solos residuais, em decorrência de núcleos cumuláticos de acessórios (zircão, apatita, alanita e outros), por exemplo, que podem contribuir para variações locais expressivas de U, Th, Ra e Rn; (iv) permeabilidade não homogênea dos solos, que pode exercer um controle sobre a emanação de Rn; e (v) proximidade com o lençol freático. Assim, solos com baixa permeabilidade ou solos argilosos servem como "armadilhas" ou "tampões" que impedem a percolação de Rn; e (v) proximidade do lençol freático, que pode gerar erro nas medições devido a entrada de água na sonda, considerando que o equipamento utilizado foi configurado para medições de Rn no ar do solo e não na água. Além disso, no lençol freático, o fluxo de Rn está controlado pelo fluxo da água, diminuindo sua emanação à superfície (Rebelo et al., 2003)
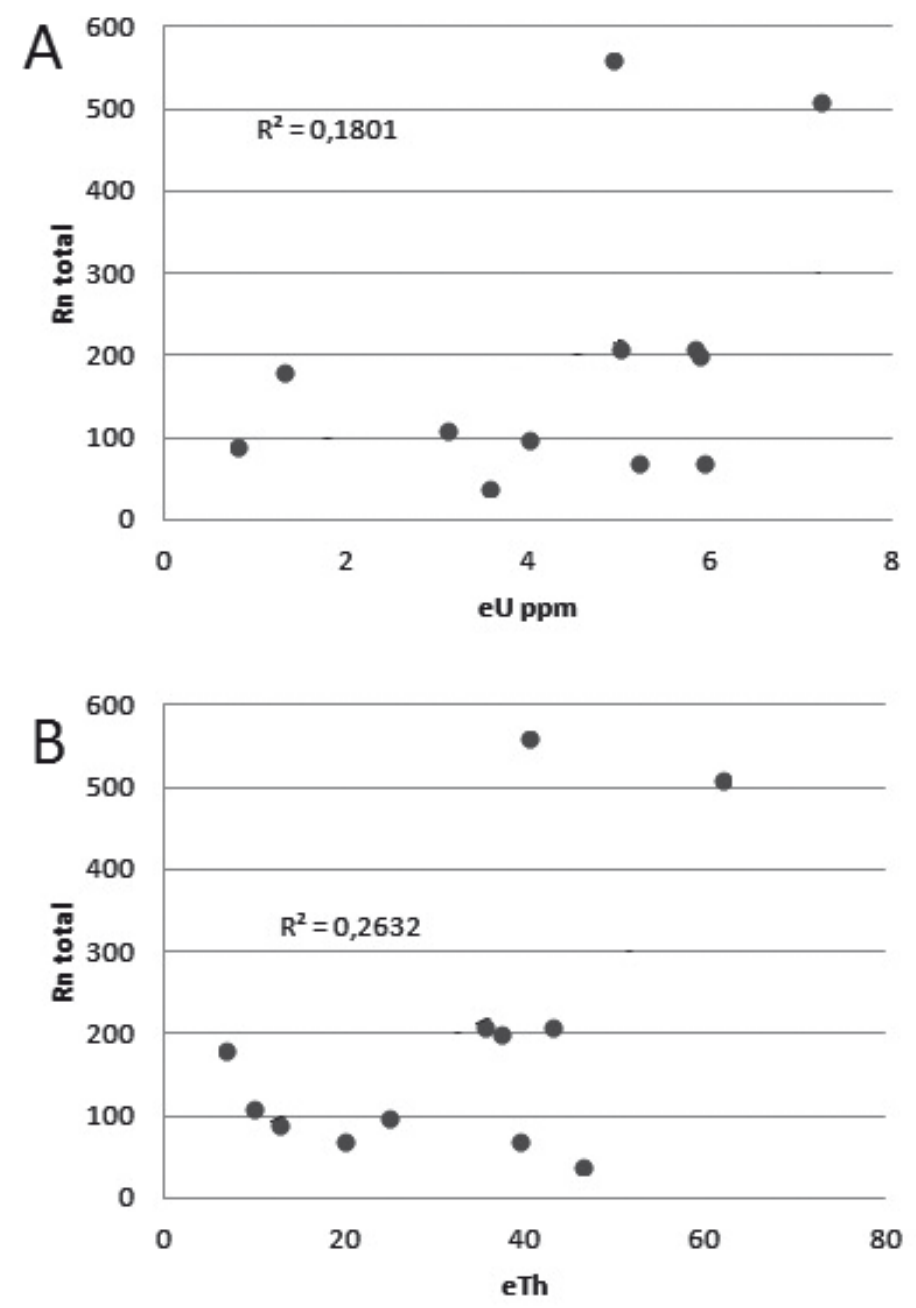

Figura 11. Relações de Rn total vs. eU (A) e Rn total vs. eTh (B). 


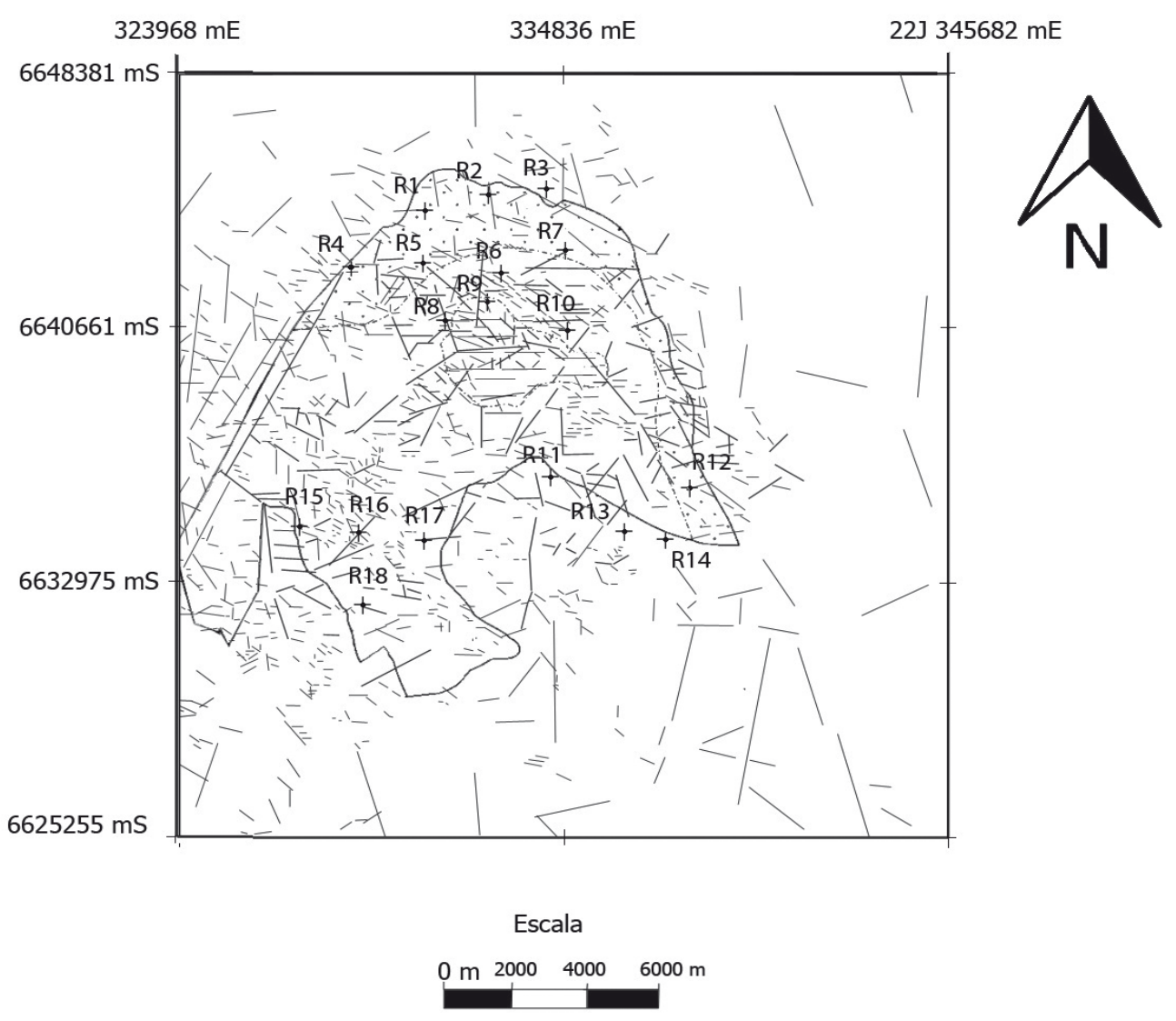

Figura 12. Principais lineamentos tectônicos da área de estudo e localização dos pontos de medida de Rn (R representa o ponto de medida de Rn no solo).
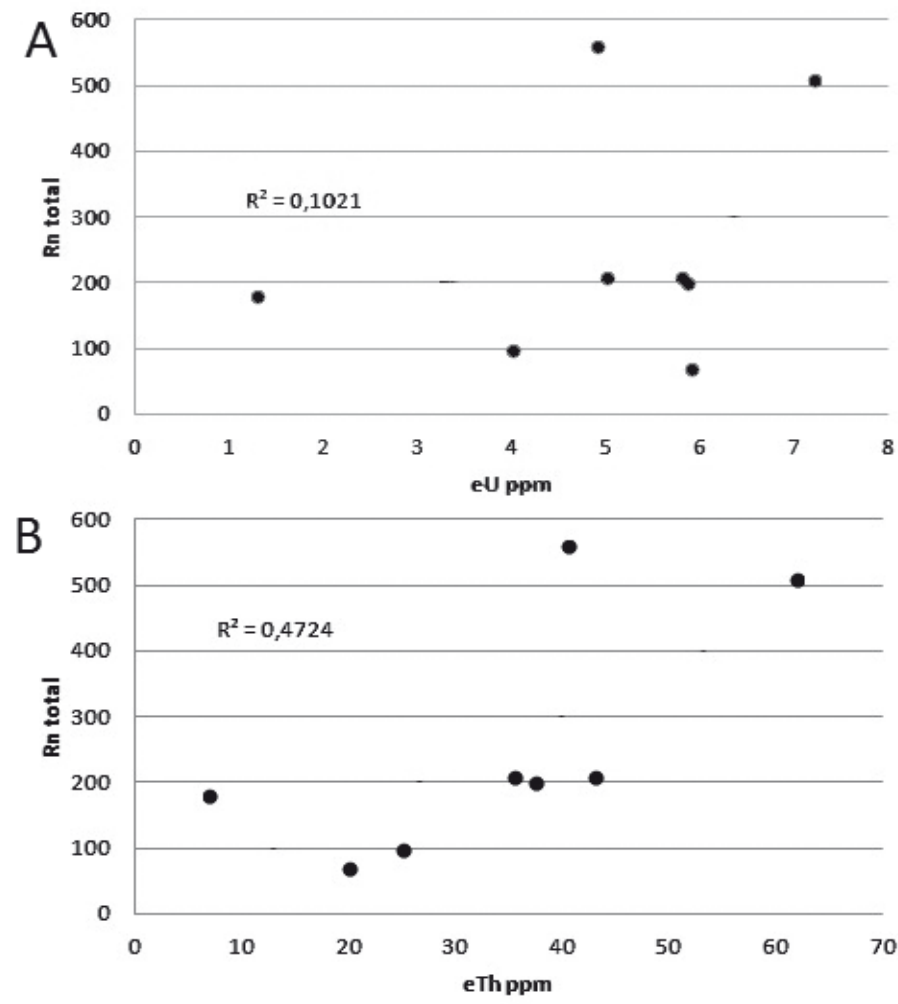

Figura 13. Relações de Rn total vs. eU (A) e Rn total vs. eTh determinadas nas áreas com alta densidade de fraturas (B). 
As concentrações de ${ }^{220} \mathrm{Rn}$ e ${ }^{222} \mathrm{Rn}$ no ar dos solos do Maciço Sienítico Piquiri (Tab. 3) são elevadas se comparadas às concentrações registradas em outros países (Shweikani \& Hushari, 2005; Gomes et al., 2013; Wang et al., 2014) e, igualmente, maiores que as concentrações determinadas por Fianco et al. (2012) em solos da região de Porto Alegre (RS), nos quais o valor máximo registrado foi de $31 \mathrm{kBq} / \mathrm{m}^{3} \pm 1 \mathrm{kBq} / \mathrm{m}^{3}$.

\section{Conclusões}

A Fácies da Borda do Maciço Sienítico Piquiri apresenta menores valores de radiação gama, concentração de K, eU e eTh do que a Fácies Principal do corpo sienítico. 0 mapa de distribuição de K obtido a partir de gamaespectrometria delimita os contatos litológicos do Maciço Sienítico Piquiri, porque está associado ao feldspato potássico, mineral principal das rochas sieníticas. Por outro lado, as maiores concentrações de eTh obtidas neste trabalho aparecem na zona Norte e Sul da Fácies Principal do Maciço Sienítico Piquiri, e os solos e rochas desta zona também apresentam altos valores de eU, com as maiores concentrações na zona Norte da Fácies Principal.

Os solos do Maciço Sienítico Piquiri apresentam elevadas concentrações de Rn, localizando-se as menores concentrações na Fácies da Borda, enquanto as maiores concentrações, na Fácies Principal do corpo sienítico. As altas concentrações de ${ }^{222} \mathrm{Rn}$ estão localizadas na zona Norte da Fácies Principal, podendo estar relacionadas com a alta concentração de eU. As maiores concentrações de ${ }^{220} \mathrm{Rn}$ estão presentes na zona Sul da Fácies Principal do Maciço Sienítico Piquiri, relacionadas à alta concentração de eTh destes solos.

$\mathrm{Na}$ área de abrangência do Maciço Sienítico Piquiri é possível que exista um potencial risco de câncer de pulmão em humanos devido ao Rn, que é maior na zona Norte da Fácies Principal. Não obstante, é preciso determinar a concentração do gás Rn dentro de casas e construções desta área, para saber se existe relação entre os teores do gás Rn e incidência de câncer de pulmão em pessoas que vivem na região.

Agradecimentos - Os autores agradecem ao CNEN pelo acesso aos equipamentos utilizados. Este trabalho está relacionado à Dissertação de Mestrado do primeiro autor, desenvolvida junto ao Programa de Pós-graduação de Geociências da UFRGS, com bolsa do CNPq.

\section{Referências}

Appleton, J.D. 2005. Radon in air and water. In: Selinus, 0. \& Smedley, P. (Eds). Essentials of medical geology: impacts of the natural environment on public health. Londres, British Geological Survey. NERC, p. 227 262.

Bitencourt, M.F. \& Nardi, L.V.S. 2000. Tectonic setting and sources of magmatism related to the southern Brazilian Shear Belt. Revista Brasileira de Geociências, 30: 184 - 187.

Buffon, S.A. 2002. Integração de dados geofísicos e geológicos na avaliação ambiental e epidemiológica de radiações naturais (radônio) no escudo Sul-Riograndense (RS - Brasil). Porto Alegre, 150p. Dissertação de Mestrado, Programa de Pós-graduação em Engenharia de Minas, Metalúrgica e de Materiais, Escola de Engenharia, Universidade Federal do Rio Grande do Sul.

Castro, M.S.M., Vieira, V.A. \& Assunção, R.M. 2004. Padrões espaço-temporais da mortalidade por câncer de pulmão no sul do Brasil. Revista Brasileira de Epidemiologia, 7(2): 131 - 143.

Ferronsky, V.I. \& Polyakov, V.A. 2012. Isotopes of the Earth's Hydrosphere. Londres, Springer, 625p.

Fianco, A.C.B., Roisenberg, A. \& Bonotto, D.M. 2012. Radon emissions related to the granitic Precambrian shield in southern Brazil. Isotopes in Environmental and Health Studies, 48(1): 122 - 131.

Gomes, M.E.P., Martins, L.M.O., Neves, L.J.P.F. \& Pereira, A.J.C.S. 2013. Natural radiation and geochemical data for rocks and soils, in the North International Douro Cliffs (NE Portugal). Journal of Geochemical Exploration, 130: 60- 64.

Hartmann, L.A., Chemale Jr., F. \& Philipp, R.P. 2007. Evolução geotectônica do Rio Grande do Sul no Pré-Cambriano. In: Iannuzzi R. \& Frantz J.C. (Eds.). 50 anos de Geologia: Instituto de Geociências: Contrubuições. Brasil. Editora Comunicação e Identidade, p. $97-123$.

IAEA. International Atomic Energy Agency. 2003 Guidelines for radioelement mapping using gamma ray spectrometry data. Viena, IAEA-TECDOC-1363, 179p.

Jost, H., Brod, J.A., Holz, M., Kuhn, A., Flor, M.A., Kronbauer, A. \& Dillenburg, S. 1985. Geologia estrutural, petrografia e petrologia do Sienito Piquiri (Proterozóico Superior), Rio Grande do Sul. In: SIMPÓSIO SUL-BRASILEIRO DE GEOLOGIA, 2, Florianópolis, SC, Brasil, SBG, Anais..., p. 63 - 80.

Kitto, M.E. \& Green J.G. 2008. Mapping the indoor radon potential in New York at the township level. Atmospheric Environment, 42: 8007 - 8014.

Manohar, S.N., Meijer, H.A.J. \& Herber, M.A. 2013. Radon flux maps for the Netherlands and Europe using terrestrial gamma radiation derived from soil radionuclides. Atmospheric Environment, 81: 399- 412.

Milsom, J. 2003. Field Geophysics. 3a. ed., Chichester, John Wiley \& Sons Ltd, 232p.

Nardi, L.V.S., Cid, J.P. \& Bitencourt, M.F. 2007. Minette mafic microgranular enclaves and their relationship 
to host syenites in systems formed at mantle pressures: major and trace element evidence from the Piquiri Syenite Massif, southernmost Brazil. Mineralogy and Petrology, 91: 101 - 116.

Nardi, L.V.S., Plá-Cid, J., Bitencourt, M.F. \& Stabel, L.Z. 2008. Geochemistry and petrogenesis of post-collisional ultrapotassic syenites and granites from southernmost Brazil: the Piquiri Syenite Massif. Anais da Academia Brasileira de Ciências, 80(2): 353 - 371.

Pascale, F.T., Francesco, S., Carbone, P., Cuoco, E. \& Tedesco, D. 2014. Dry soil diurnal quase-periodic oscillations in soil ${ }^{222} \mathrm{Rn}$ concentrations. Radiation Measurements, 66: $31-41$.

Pereira, C.M.A. 2009. Mapeamento de aquíferos fraturados empregando métodos geoelétricos e emanação natural de radônio. São Paulo, 63p. Dissertação de Mestrado, Programa de Pós-graduação em Recursos Minerais e Hidrologia, Instituto de Geociências, Universidade de São Paulo.

Philipp, R.P., Machado, R., Nardi, L.V.S. \& Lafon, J.M. 2002. O magmatismo granítico neoproterozóico do Batólito Pelotas no sul do Brasil: Novos dados e revisão da geocronologia regional. Revista Brasileira de Geociências, 32(2): 277 - 290.

Rebelo, A.M.A., Bittencourt, A.V.L. \& Mantovani, L.E. 2003. Modelos de exalação de radônio em paisagens tropicais úmidas sobre granito. Boletim Paranaense de Geociências, 52: 61 - 76.

Santos, C.E.L. 2008. Determinação dos processos de enriquecimento e das concentrações de radônio em minas subterrâneas de fluorita e carvão do Estado de Santa

Man. 566.

Editores: Ana Maria P. Mizusaki \& Maria do Carmo

Lima e Cunha.
Catarina: critérios para avaliação dos riscos radiológicos. Porto Alegre, 137p. Dissertação de Mestrado, Programa de Pós-graduação em Geociências, Instituto de Geociências, Universidade Federal do Rio Grande do Sul.

Silva, A.A.R. 2005. Radônio e filhos em residências da cidade de São Paulo. São Paulo, 119p. Tese de Doutorado, Programa de Pós-graduação em Física, Instituto de Física, Universidade de São Paulo.

Shweikani, R. \& Hushari, M. 2005. The correlations between radon in soil gas and its exhalation and concentration in air in the southern part of Syria. Radiation Measurements, 40: 699 - 703.

Smethurst, M.A., Strand, T., Sundal, A.V. \& Rudjord, A.L. 2008. Large-scale radon hazard evaluation in the Oslofjord region of Norway utilizing indoor radon concentrations, airborne gamma ray spectrometry and geological mapping. Science of the Total Environment, 407: 379 - 393.

Stabel, L.Z., Nardi, L.V.S. \& Cid, J.P. 2001. Química mineral e evolução petrológica do sienito Piquiri magmatismo shoshonítico, neoproterozóico, pós-colisional no sul do Brasil. Revista Brasileira de Geociências, 31(2): $211-222$.

Wang, X., Li, Y., Du, J. \& Zhou, X. 2014. Correlations between radon in soil gas and the activity of seismogenic faults in the Tangshan area, North China. Radiations Measurements, 60: 8 - 14 .

WHO. World Health Organization. 2009. WHO handbook on indoor radon: a public health perspective. Genebra, WHO, 95p. 